\title{
Effects of physical exercise and nutritional guidance on metabolic syndrome in obese adolescents
}

\section{Efeito do exercício físico e da orientação nutricional na síndrome metabólica em adolescentes obesos}

Leite N', Milano GE', Cieslak F', Lopes WA', Rodacki A', Radominski RB²

\begin{abstract}
Objectives: To analyze the effects of physical exercise and nutritional guidance on body composition, physical fitness, lipid profile and insulin resistance among obese adolescents with and without metabolic syndrome. Methods: Sixty-four obese adolescents (26 boys), 10-16 years of age, were divided into two groups: with metabolic syndrome $(n=29)$ and without metabolic syndrome $(n=35)$. They were classified as having metabolic syndrome if they met three or more criteria for age and sex according to the Adult Treatment Panel III (ATP III). Blood pressure, waist circumference, maximum oxygen uptake $\left(\mathrm{VO}_{2 \text { peak }}\right)$, blood glucose, blood insulin, homeostatic model assessment (HOMA-IR), quantitative insulin sensitivity check index (QUICKI) and lipid profile were assessed at baseline and after 12 weeks of intervention. Both groups participated in 12 weeks of physical education and two nutritional guidance sessions. Each physical education session consisted of 50 min indoor cycling, 50 min of walking/running and 20 min of stretching, three times a week. Results: Fifty-five participants (with metabolic syndrome=25; without metabolic syndrome=30) completed the treatment. After 12 weeks, both groups showed reductions in body weight, BMI z-score, waist circumference, fat mass and triglycerides; and increases in height, $\mathrm{HDL}-\mathrm{C}$ and $\mathrm{VO}_{\text {2peak }}(\mathrm{p}<0.05)$. In addition, the group with metabolic syndrome presented reduced systolic blood pressure and increased insulin sensitivity $(p<0.05)$. The risk factors for metabolic syndrome decreased by $72 \%$. Conclusion: Following the multidisciplinary intervention, the risk factors decreased, with improvements in physical fitness and metabolic profile. The multidisciplinary intervention was effective in reducing metabolic syndrome.
\end{abstract}

Key words: cardiovascular diseases; physical exercise; obesity.

\section{Resumo}

Objetivos: Analisar os efeitos de exercícios físicos (EF) e orientação nutricional (ON) sobre a composição corporal, aptidão física, perfil lipídico e resistência insulínica em adolescentes obesos com e sem síndrome metabólica (SM). Métodos: 64 obesos (26 meninos), com idade entre 10 a 16 anos, divididos em dois grupos: com SM ( $n=29)$ e sem SM ( $n=35)$. Utilizou-se como critério de classificação de SM a presença de três ou mais critérios para idade e sexo de acordo com Adult Treatment Panel III (ATP III). Mensuraram-se antes e após 12 semanas de intervenção: pressão arterial, circunferência abdominal, consumo máximo de oxigênio (VO2 ${ }_{\text {pico }}$ ), glicemia, insulinemia, Homeostatic Metabolic Assessments (HOMA-IR), Quantitative Insulin Sensitivity Check Index (QUICKI) e perfil lipídico. Os dois grupos participaram de 12 semanas de EF e duas sessões de ON. Cada sessão de EF consistiu em 50 minutos de ciclismo indoor, 50 minutos de caminhada e 20 minutos de alongamento, três vezes por semana. Resultados: 55 sujeitos (com SM=25; sem SM=30) completaram o tratamento. Após 12 semanas, houve diminuição na massa corporal, IMC escore-z, circunferência abdominal, massa gorda, TG e aumento na estatura, $\mathrm{HDL}-\mathrm{C}$ e VO2 $2_{\text {pico, }}$ em ambos os grupos. Além disso, houve uma redução na pressão arterial sistólica, aumento na sensibilidade à insulina $(p<0,05)$ no grupo com SM. Os fatores de risco para SM diminuíram em $72 \%$. Conclusão: Após a intervenção multidisciplinar, houve uma redução nos fatores de risco, melhorando a aptidão física e perfil metabólico. A intervenção multidisciplinar foi efetiva para redução da SM.

Palavras-chave: doenças cardiovasculares; exercício físico; obesidade.

\footnotetext{
Graduate Program in Physical Education, Department of Physical Education, Universidade Federal do Paraná (UFPR), Curitiba (PR), Brazil

${ }^{2}$ Graduate Program in Internal Medicine, Department of Medicine, UFPR

Correspondece to: Neiva Leite, Departamento de Educação Física, Núcleo de Pesquisa em Qualidade de Vida, UFPR, Travessa Coração de Maria, 92 , BR 116 - km 95 - Jardim Botânico, CEP 80215-370, Curitiba (PR), e-mail: neivaleite@gmail.com
} 


\section{Introduction $: \therefore$.}

Metabolic syndrome is characterized by the presence of cardiovascular risk factors, associated with the development of atherosclerotic cardiovascular disease and type 2 diabetes ${ }^{1}$. The prevalence of metabolic syndrome in children and adolescents is associated with obesity ${ }^{2,3}$ and increased serum insulin levels ${ }^{4}$. Diagnosis and treatment of metabolic syndrome are important in pediatric populations because obesity-related problems may appear early in childhood and persist into adulthood $^{3}$, with high levels of morbidity and mortality ${ }^{5}$.

Regular physical activity and nutritional guidance are among the therapeutic actions used to reduce metabolic syndrome in adults $^{5-6}$. Exercise and nutritional interventions seem to be a suitable, if not ideal, therapy for metabolic syndrome ${ }^{5}$, because aerobic exercises ${ }^{7}$ and weight $\operatorname{loss}^{8-10}$ modulate insulin sensitivity $^{5}$ and influence cardiovascular risk factors ${ }^{1,11-13}$. Although exercise is an important factor influencing metabolic syndrome and obesity ${ }^{5-6}$, only a few interventional studies have applied exercise as therapeutic treatment for children ${ }^{3}$ and adolescents ${ }^{5-14}$ with cardiovascular risk factors. In addition, these studies have not used clear criteria to diagnose metabolic syndrome.

The prevalence of metabolic syndrome in children has been diagnosed using criteria designed for adults ${ }^{2-4,15-18}$ and are generally based on the presence of three or more chronic diseases such as cardiovascular disease, dyslipidemia, arterial hypertension, insulin resistance and type 2 diabetes mellitus. Taking these adult-based criteria, the prevalence of metabolic syndrome may reach more than $50 \%$ in a severely obese pediatric population ${ }^{2,14}$ because obesity is closely related to all these risk factors.

To the best of the authors' knowledge, the effect of exercise intervention programs on adolescents with metabolic syndrome has been little investigated ${ }^{19}$. This is especially true because such investigations require a multidisciplinary team and longterm study to detect the changes induced in this population ${ }^{20-21}$. Thus, the aim of the present study was to evaluate the effect of physical training and nutritional guidance on body composition, physical fitness, lipid profile and insulin resistance among obese adolescents with and without metabolic syndrome. It was hypothesized that the participants with metabolic syndrome would achieve reductions in the metabolic indicators and insulin resistance, in comparison with the other group.

\section{Methods : :}

\section{Participants}

Sixty-four obese participants aged between 10 and 16 years, with body mass index (BMI) greater than the $90^{\text {th }}$ percentile (CDC, 2000)22, were recruited from the pediatric endocrinology outpatient clinic and from five public schools in the vicinity of the hospital (within $2 \mathrm{~km}$ ). Participants were invited to participate in the intervention group on the basis of their BMI, and their agreement to participate depended on their availability and parental permission. The study was granted approval by the Ethics Committee of Universidade Federal do Paraná (protocol no. CEP/HC 765.184/2003-11). Participants were excluded if they presented: diabetes; use of medication to control blood pressure, glucose levels or lipid metabolism; use of drugs that influence appetite (e.g. glucocorticoids, insulin sensitizers or psychotropic drugs); or orthopedic limitations (e.g. fracture or injury).

The participants were allocated to one of the two experimental groups: obese with metabolic syndrome (WMS) $(n=29)$ and obese without metabolic syndrome (NMS) (n=35). Fifty-five participants completed the 12 weeks of the intervention protocol with at least $60 \%$ attendance. The number of dropouts was similar in the two groups (WMS, $n=25$; NMS, $n=30$ ).

The procedures for calculating the sample size were based on data from our study and the effect size calculated was 0.7 (power=0.80; alpha=0.05), yielding a total of 21 participants for each group.

\section{Intervention design}

The obese children and adolescents were invited to participate in a three-month exercise and nutritional program. The intervention consisted of aerobic exercise and a nutritional program for managing obesity and metabolic syndrome. The professionals involved in the program included a physiologist, a nutritionist, six physical educators, two physicians and three nurses. All measurements were performed before and after the treatment, in both groups.

\section{Anthropometry}

Weight was measured to the nearest $0.1 \mathrm{~kg}$ (Filizola ${ }^{\circledR}$, São Paulo, SP, Brazil). Height was measured to the nearest $0.1 \mathrm{~cm}$ (Ayrton Corporation ${ }^{\circledR}$ ). Height and body weight were measured on the same day. The body mass index (BMI) was calculated as the weight in kilograms divided by the square of the height in meters. The BMI was converted to z-scores by subtracting the value corresponding to the $50^{\text {th }}$ percentile of BMI, divided by the standard deviation for the population, in accordance with figures released by the CDC, for all ages and both genders ${ }^{22}$.

The waist circumference was measured in centimeters using a non-extendable flexible tape, with precision of $0.1 \mathrm{~cm}$. The tape was applied above the iliac crest, parallel to the ground, with the individual standing with the abdomen relaxed, arms 
along the body and feet together. The cutoff was taken as the $75^{\text {th }}$ percentile, or greater according to age and $\operatorname{sex}^{23}$.

In addition, body composition was determined by bioelectrical impedance using a tetra polar machine (Biodynamics ${ }^{\circledR}$ ). Body composition measurements were made in the morning, after 10 to 12 hours of overnight fasting. The fat-free mass, fat mass and percentage of body fat mass $(\% \mathrm{BF})$ were calculated using the equations validated by Houtkooper et al. ${ }^{24}$.

\section{Diagnosis of metabolic syndrome}

Metabolic syndrome was diagnosed using the Adult Treatment Panel (ATP III) criteria, which consider the presence of three or more of the five criteria for age and gender: HDLcholesterol (HDL-C) $<45 \mathrm{mg} / \mathrm{dl}$; triglyceride concentration $\geq 100 \mathrm{mg} / \mathrm{dl}^{25}$, waist circumference $\geq 75^{\text {th }}$ percentile ${ }^{23}$, fasting glucose concentration $\geq 100 \mathrm{mg} / \mathrm{dl}^{26}$ and systolic or diastolic blood pressure $\geq 90^{\text {th }}$ percentile ${ }^{27}$.

\section{Metabolic variables}

Blood samples were collected in the pediatric endocrinology unit at around 7:30 a.m., after a period of at least 12 hours of fasting. Glucose tolerance, insulin, triglycerides, total cholesterol and fractions were measured using automated standard methods. Glucose (glucose 120) and insulin (insulin 120) measurements were repeated after two hours of glucose overload. Insulin resistance was assessed by means of the homeostatic model assessment (HOMA-IR) index.

HOMA-IR was calculated as ( fasting blood glucose $[\mu \mathrm{U} / \mathrm{ml}]$ $\mathrm{x}$ insulin $[\mathrm{mMol} / \mathrm{l}] / 22.5)^{28}$. The quantitative insulin sensitivity check index (QUICKI) was determined in order to evaluate insulin sensitivity ${ }^{29}$. QUICKI was calculated as $1 /[\log$ ( fasting insulin)(mU/ml) x log ( fasting blood glucose) $(\mathrm{mMol} / \mathrm{l})]^{29}$.

\section{Blood pressure}

Blood pressure was measured in the right arm using an aneroid sphygmomanometer (Welch Allyn, Arden, NC, USA), with the appropriate cuff size for the individual's arm circumference, with the participants in the seated position, after 10 minutes of rest. The first sound was used to define systolic blood pressure, and the disappearance of sound was used to define diastolic blood pressure. The values obtained were classified according to the tables of specific percentiles for children and adolescents ${ }^{30}$.

\section{Aerobic fitness $\left(\mathrm{VO}_{\text {2peak }}\right)$}

The participants' aerobic fitness was measured during a cycling task on a cycle ergometer and during a walking task on a treadmill, following the protocol suggested by McMaster ${ }^{31}$. The cycling frequency was $60 \mathrm{rpm}$, with a starting load of $25 \mathrm{~W}$ that was gradually increased until reaching the participants' maximum effort. The treadmill assessment followed a modified version of Balke's protocol ${ }^{32}$. A minimum of 24 hours and a maximum of one week between the aerobic fitness tests were imposed.

For the cardiorespiratory analysis, a direct gas analyzer was used, with the respiratory and metabolic variables measured through respiratory gas exchanges with a computerized (Intel 486, DX2, $66 \mathrm{MHz}$ ) metabolic system (Vista XT metabolic system, USA), which provided information on oxygen uptake $\left(\mathrm{VO}_{2}\right)$, carbon dioxide production $\left(\mathrm{VCO}_{2}\right)$, pulmonary ventilation (VE), respiratory equivalents of oxygen $\left(\mathrm{LV} / \mathrm{VO}_{2}\right)$ and carbon dioxide $\left(\mathrm{LV} / \mathrm{VCO}_{2}\right)$, and respiratory exchange ratio $\left(\mathrm{RER}=\mathrm{VCO}_{2} / \mathrm{VO}_{2}\right)$. These variables were monitored every 15 seconds. Heart rate was monitored using a heart beat monitor (Polar - A1).

In order to determine whether the $\mathrm{VO}_{2}$ attained was the maximum, at least two of the following criteria were observed: a) exhaustion or inability to maintain the required speed; b) $\mathrm{RER}>1.3$; c) maximum heart rate $\left(\mathrm{HR}_{\text {max }}>190 \mathrm{bpm}\right)$.

\section{Intervention}

\section{Exercise protocol}

All participants in both groups were required to attend exercise sessions on a regular basis (two to three times per week, for 12 weeks). The exercises consisted of 50 minutes of indoor cycling, 50 minutes of outdoor walking/running and 20 minutes of stretching exercises, which were conducted by a certified and experienced physical fitness instructor. The exercise prescription was based on the data collected from the baseline treadmill test. During the first four weeks (12 sessions), the intensity was set at $35-55 \%$ of $\mathrm{VO}_{2 \text { peak }}$, and this was increased to $55-75 \%$ during the last weeks. Heart rate was monitored during all the sessions, every 15 minutes. Instructors encouraged and helped participants to increase their exercise intensity, in order to maintain their heart rate within the target zones.

\section{Nutritional protocol}

The obese participants with and without metabolic syndrome received nutritional guidance four times during the program, twice in individual sessions (baseline and after 12 weeks) and twice in groups ( fourth and eighth weeks). The participants' diets were monitored by means of three-day dietary recall, in accordance with the standards of the American Dietetic Association ${ }^{33}$. The prescribed nutritional guidance was based on an exchange list, by reducing 500 kilocalories (kcal) 
from the calorie total in the diet, in order to promote a $0.5 \mathrm{~kg}$ reduction per week $\left(2 \mathrm{~kg}\right.$ per month) ${ }^{34}$.

\section{Clinical evaluation}

The medical follow-up included the initial medical history, physical examination, pubertal developmental stage ${ }^{35}$ and appropriate tests followed by regular clinical surveillance by a pediatrician and an endocrinologist before and after the intervention. All patients underwent multidisciplinary therapy.

\section{Statistical procedures}

Standard descriptive statistics were calculated for all variables. The normality of the data distribution was determined using the Shapiro-Wilk test and the homogeneity of the variance of these data was assessed using Levene's test. $\log _{10}$ transformations were used to normalize non-normally distributed variables (systolic blood pressure, diastolic blood pressure, total cholesterol, HDL-C, LDL-C, triglycerides, glucose and QUICKI). Untransformed data were used to facilitate interpretation. The lack of significant differences between the genders ( $p>0.05$ ) made it possible to discard sexual differences. Multivariate 2x2 analysis of variance (MANOVA) for repeated measurements was used to examine differences and treatment effects (group $\mathrm{x}$ time). Mauchly's test was used to determine whether sphericity was violated $(<0.75)$. Greenhouse-Geiser adjustments were made to $\mathrm{p}$ values for treatment effects to account for potential violations of repeated measures. The alpha level was set at $5 \%$ for all comparisons and the statistic analyses were conducted using specific software (Statistica version 5.5).

\section{Results $: \therefore$.}

The prevalence of metabolic syndrome was $45 \%$ among all the participants. After 12 weeks, the dropout (14\%) and adherence $(86 \%)$ rates were the same for both groups (obese participants with metabolic syndrome: $n=25$; obese participants without metabolic syndrome: $\mathrm{n}=30$ ). There were no differences in the proportions of girls and boys between the two groups, either at the $\operatorname{start}\left(\chi^{2}=2.71 ; \mathrm{p}=0.10\right)$ or at the end $\left(\chi^{2}=2.71 ; \mathrm{p}=0.10\right)$ of the study.

The participants' initial conditions were similar between the groups, with regard to all the variables selected. Before the training program, the obese participants with metabolic syndrome showed higher total body mass $(\mathrm{p}=0.008), \% \mathrm{BF}$ $(\mathrm{p}<0.001)$ and fat mass $(\mathrm{p}<0.001)$ and lower $\mathrm{VO}_{2 \text { peak }}$ relative to body weight $\left(\mathrm{VO}_{\text {2peak }} \mathrm{ml} / \mathrm{kg} / \mathrm{min}\right)(\mathrm{p}=0.001)$ than the obese participants without metabolic syndrome. In addition, systolic blood pressure ( $\mathrm{p}=0.002)$, diastolic blood pressure $(\mathrm{p}<0.001)$, insulin $(\mathrm{p}=0.012)$, triglycerides $(\mathrm{p}<0.001)$ and HOMA-IR $(\mathrm{p}=0.027)$ were higher in the obese participants with metabolic syndrome than in those without the syndrome. QUICKI was lower $(\mathrm{p}=0.030)$ in the obese participants with metabolic syndrome than in those without the syndrome. The other metabolic variables (triglycerides, HDL-C and LDL-C) were similar ( $p>0.05)$ in the two groups at baseline.

After the training period, the obese participants with metabolic syndrome showed significant reductions in total body mass $(\mathrm{p}=0.001)$, BMI $\mathrm{z}$-score $(\mathrm{p}<0.001)$, waist circumference $(p<0.001), \% B F(p=0.001)$, fat mass $(p=0.001)$, resting heart rate ( $\mathrm{p}=0.003)$ and $\mathrm{HR}_{\text {max }}(\mathrm{p}=0.022)$, compared with their respective baseline values. Height $(\mathrm{p}<0.001)$ and $\mathrm{VO}_{2 \text { peak }} \mathrm{ml} / \mathrm{kg} / \mathrm{min}$ increased $(p=0.011)$ in comparison with baseline values. The fat-free mass remained unchanged $(p>0.05)$ in the obese participants with metabolic syndrome after training.

The obese participants without metabolic syndrome showed significant reductions in total body mass $(p=0.001)$, BMI z-score $(p<0.001)$, waist circumference $(p<0.001), \%$ BF $(\mathrm{p}=0.001)$, fat mass $(\mathrm{p}=0.001)$, RHR $(\mathrm{p}=0.019)$ and $\mathrm{HR}_{\max }$ $(p=0.001)$ after the training period. As with the obese participants with metabolic syndrome, height $(\mathrm{p}<0.001)$ and $\mathrm{VO}_{2 \text { peak }}$ $\mathrm{ml} / \mathrm{kg} / \mathrm{min}(\mathrm{p}<0.001)$ also increased after training among the obese participants without metabolic syndrome. The fat-free mass was unchanged after training $(\mathrm{p}>0.05)$. Conversely, $\mathrm{VO}_{2 \text { peak }}$ adjusted for fat-free mass $(\mathrm{ml} / \mathrm{kgFFM} / \mathrm{min})$ increased $(\mathrm{p}=0.002)$ in response to training.

Comparison of the training effects between the groups showed the reductions in total body mass $(\mathrm{p}=0.012)$ and BMI $\mathrm{z}$-score $(\mathrm{p}=0.01)$ and the increases in fat-free mass $(\mathrm{p}=0.04)$ among the obese participants without metabolic syndrome were greater than among those with the syndrome. The anthropometric and physical fitness profiles are shown in Table 1.

Table 2 shows the metabolic and lipid profiles. The obese participants with metabolic syndrome showed significant reductions in triglycerides ( $\mathrm{p}<0.001)$, glucose $120(\mathrm{p}=0.005)$, insulin 120 $(\mathrm{p}<0.001)$ and systolic blood pressure $(\mathrm{p}=0.024)$ and increases in HDL-C ( $\mathrm{p}<0.001)$ and QUICKI ( $\mathrm{p}=0.021)$ after 12 weeks of training. There were no differences $(p>0.05)$ in diastolic blood pressure, total cholesterol, LDL-C, glucose, insulin and HOMA-IR. The obese participants without metabolic syndrome presented significant reductions in triglycerides $(\mathrm{p}=0.004)$, glucose 120 ( $\mathrm{p}=0.001)$ and insulin $120(\mathrm{p}=0.01)$ and an increase in HDL-C $(p<0.001)$ in response to training. There were no differences ( $p>0.05$ ) in systolic blood pressure, diastolic blood pressure, total cholesterol, LDL-C, glucose, insulin, HOMA-IR and QUICKI.

Comparison between the groups showed the reductions in systolic blood pressure $(\mathrm{p}=0.001)$, diastolic blood 
pressure $(\mathrm{p}=0.003)$, triglycerides $(\mathrm{p}<0.001)$, insulin $(\mathrm{p}=0.015)$ and HOMA-IR ( $\mathrm{p}=0.013)$ and increases in QUICKI ( $\mathrm{p}=0.013)$ among the obese participants with metabolic syndrome were greater than among those without the syndrome, following the experimental procedures. However, the glucose 120 level decreased $(\mathrm{p}=0.037)$ and the HDL-C level increased $(\mathrm{p}=0.010)$ more among the obese participants without metabolic syndrome than among those with the syndrome.

The prevalence of metabolic syndrome decreased from $45 \%$ before training to $13 \%$ after training. Among the obese participants with metabolic syndrome, the presence of risk factors for metabolic syndrome decreased in 18 (72\%) of the 25 adolescents $(\mathrm{p}<0.0001)$. The analysis on changes in risk factors for metabolic syndrome is summarized in Figure 1. There were reductions in fasting triglyceride concentrations $<100 \mathrm{mg} / \mathrm{dl}$ in 11 participants (55\%, $\mathrm{p}=0.0126$ ), glucose $<100 \mathrm{mg} / \mathrm{dl}$ in two participants (29\%), waist circumference $<75^{\text {th }}$ percentile in one participant (4\%) and systolic or diastolic blood pressure $<90^{\text {th }}$ percentile in five participants (38\%). There were increases in HDL-C level $>45 \mathrm{mg} / \mathrm{dl}$ in 12 participants $(57 \%$, $\mathrm{p}=0.007)$.

Table 1. Anthropometric and physical fitness profiles of obese adolescents - with metabolic syndrome (WMS) and without metabolic syndrome (NMS).

\begin{tabular}{|c|c|c|c|c|c|c|c|c|c|c|}
\hline \multirow{2}{*}{ Variable } & \multicolumn{4}{|c|}{ WMS $(n=25)$} & \multicolumn{4}{|c|}{ NMS $(n=30)$} & \multicolumn{2}{|c|}{$\begin{array}{l}\text { WMS versus } \\
\text { NMS }\end{array}$} \\
\hline & Before $(n=25)$ & After $(n=25)$ & $\mathrm{F}$ & $p$ value & Before $(n=30)$ & After $(n=30)$ & $\mathrm{F}$ & $p$ value & $\mathrm{F}$ & $p$ value \\
\hline Total body mass (kg) & $81.86 \pm 15.69^{a, c}$ & $79.78 \pm 15.77^{a, c}$ & 14.040 & 0.001 & $72.60 \pm 10.89^{b, c}$ & $70.44 \pm 10.72^{b, c}$ & 22.967 & $<0.001$ & 6.765 & 0.012 \\
\hline Height (cm) & $162.80 \pm 8.15^{a}$ & $164.36 \pm 8.37^{a}$ & 45.056 & $<0.001$ & $159.83 \pm 7.45^{b}$ & $161.33 \pm 7.12^{b}$ & 30.875 & $<0.001$ & 2.064 & NS \\
\hline BMI z-score & $3.45 \pm 1.08^{\mathrm{a}, \mathrm{c}}$ & $2.98 \pm 1.13^{\mathrm{a}, \mathrm{c}}$ & 43.103 & $<0.001$ & $2.70 \pm 0.96^{b, c}$ & $2.25 \pm 0.96^{b, c}$ & 92.472 & $<0.001$ & 7.158 & 0.010 \\
\hline WC (cm) & $99.83 \pm 11.80^{\mathrm{a}}$ & $96.50 \pm 11.87^{\mathrm{a}}$ & 20.035 & $<0.001$ & $95.04 \pm 9.68^{b}$ & $90.20 \pm 10.06^{b}$ & 50.972 & $<0.001$ & 3.705 & NS \\
\hline$\% \mathrm{BF}$ & $37.47 \pm 5.26^{a}$ & $34.99 \pm 6.42^{\mathrm{a}}$ & 14.062 & 0.001 & $37.27 \pm 4.60^{\mathrm{b}}$ & $35.55 \pm 4.60^{b}$ & 14.097 & 0.001 & 0.141 & NS \\
\hline $\mathrm{FM}(\mathrm{kg})$ & $30.89 \pm 9.34^{a}$ & $27.60 \pm 9.36^{a}$ & 22.495 & $<0.001$ & $27.17 \pm 6.09^{b}$ & $25.67 \pm 6.60^{b}$ & 13.600 & 0.001 & 0.970 & NS \\
\hline FFM (kg) & $50.37 \pm 8.77^{c}$ & $49.64 \pm 7.79 c$ & 0.384 & NS & $45.32 \pm 6.16^{c}$ & $45.72 \pm 5.85^{c}$ & 3.730 & NS & 4.399 & 0.041 \\
\hline RHR (bpm) & $82.20 \pm 10.88^{a}$ & $74.88 \pm 9.76^{a}$ & 10.915 & 0.003 & $77.60 \pm 8.24^{b}$ & $73.46 \pm 8.23^{b}$ & 6.153 & 0.019 & 2.045 & NS \\
\hline $\mathrm{RH}_{\text {max }}$ (bpm) & $195 \pm 10.19^{\mathrm{a}}$ & $192 \pm 8.78^{\mathrm{a}}$ & 6.024 & 0.022 & $184 \pm 11.14^{b}$ & $183 \pm 11.43^{b}$ & 12.616 & 0.001 & 0.994 & NS \\
\hline $\mathrm{VO}_{2 \text { peak }} \mathrm{l} / \mathrm{min}$ & $2.93 \pm 0.54$ & $3.05 \pm 0.61$ & 1.607 & NS & $2.65 \pm 0.58$ & $2.74 \pm 0.60$ & 2.210 & NS & 3.791 & NS \\
\hline $\mathrm{VO}_{2 \text { peak. }} \mathrm{ml} / \mathrm{kg} / \mathrm{min}$ & $33.44 \pm 4.51^{\mathrm{a}}$ & $36.91 \pm 6.98^{\mathrm{a}}$ & 7.608 & 0.011 & $33.38 \pm 5.62^{b}$ & $37.48 \pm 6.60^{b}$ & 35.476 & $<0.001$ & 0.032 & NS \\
\hline $\mathrm{VO}_{2 \max } \mathrm{ml} / \mathrm{kgFMM} / \mathrm{min}$ & $54.10 \pm 6.78$ & $57.67 \pm 8.17$ & 2.085 & NS & $53.79 \pm 7.19^{b}$ & $56.77 \pm 7.08^{b}$ & 11.984 & 0.002 & 0.447 & NS \\
\hline
\end{tabular}

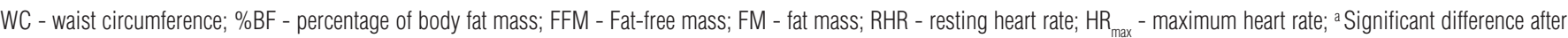
12 weeks in the group with metabolic syndrome; ${ }^{b}$ Significant difference after 12 weeks in the group without metabolic syndrome; ' ${ }^{\circ}$ Significant difference in the interaction effect between WMS and NMS groups.

Table 2. Metabolic, hemodynamic and lipid profiles among obese adolescents - with metabolic syndrome (WMS) and without metabolic syndrome (NMS).

\begin{tabular}{|c|c|c|c|c|c|c|c|c|c|c|}
\hline \multirow[t]{2}{*}{ Variable } & \multicolumn{4}{|c|}{ WMS $(n=25)$} & \multicolumn{4}{|c|}{ NMS $(n=30)$} & \multicolumn{2}{|c|}{$\begin{array}{l}\text { WMS versus } \\
\text { NMS }\end{array}$} \\
\hline & Before $(n=25)$ & After $(n=25)$ & $\mathrm{F}$ & $p$ value & Before $(n=30)$ & After $(n=30)$ & $\mathrm{F}$ & $p$ value & $\mathrm{F}$ & $p$ value \\
\hline $\mathrm{SBP}(\mathrm{mmHg})$ & $114.80 \pm 17.28^{\mathrm{a}, \mathrm{c}}$ & $107.20 \pm 14.16^{a, c}$ & 5.815 & 0.024 & $99.73 \pm 9.07^{c}$ & $99.46 \pm 9.55^{c}$ & 0.017 & NS & 13.713 & 0.001 \\
\hline $\mathrm{DBP}(\mathrm{mmHg})$ & $74.64 \pm 11.39^{c}$ & $70.56 \pm 13.86^{c}$ & 3.264 & NS & $64.26 \pm 6.92^{c}$ & $65.93 \pm 7.60^{c}$ & 1.052 & NS & 10.016 & 0.003 \\
\hline $\mathrm{TC}(\mathrm{mg} / \mathrm{dl})$ & $163.04 \pm 31.43$ & $160.64 \pm 33.52$ & 0.592 & NS & $147.16 \pm 27.01$ & $147.13 \pm 27.81$ & 0.000 & NS & 3.593 & NS \\
\hline HDL-C (mg/dl) & $39.88 \pm 6.68^{\mathrm{a}, \mathrm{c}}$ & $46.92 \pm 8.26^{\mathrm{a}, \mathrm{c}}$ & 22.444 & $<0.001$ & $43.86 \pm 6.04^{b, c}$ & $52.00 \pm 8.39^{b, c}$ & 30.818 & $<0.001$ & 7.043 & 0.010 \\
\hline LDL-C (mg/dl) & $92.96 \pm 28.20$ & $93.60 \pm 28.09$ & 0.042 & NS & $86.86 \pm 22.10$ & $82.20 \pm 22.12$ & 3.538 & NS & 1.818 & NS \\
\hline $\mathrm{TG}(\mathrm{mg} / \mathrm{dl})$ & $151.04 \pm 63.13^{\mathrm{a}, \mathrm{c}}$ & $100.44 \pm 42.43^{\mathrm{a}, \mathrm{c}}$ & 23.055 & $<0.001$ & $83.72 \pm 46.14^{b, c}$ & $64.40 \pm 26.63^{b, c}$ & 10.126 & 0.004 & 21.472 & $<0.001$ \\
\hline Glucose (mg/dl) & $93.32 \pm 9.55$ & $93.00 \pm 8.72$ & 0.045 & NS & $89.26 \pm 6.90$ & $90.73 \pm 7.83$ & 1.065 & NS & 2.568 & NS \\
\hline Glucose 120 (mg/dl) & $106.68 \pm 19.39^{\mathrm{acc}}$ & $97.44 \pm 17.63^{a, c}$ & 9.686 & 0.005 & $98.56 \pm 15.48^{b, c}$ & $88.70 \pm 12.55^{b, c}$ & 14.469 & 0.001 & 4.574 & 0.037 \\
\hline Insulin ( $\mu \mathrm{UI} / \mathrm{ml})$ & $19.62 \pm 8.47^{c}$ & $17.51 \pm 9.52^{c}$ & 2.791 & NS & $14.59 \pm 6.80^{c}$ & $12.79 \pm 6.36^{c}$ & 2.683 & NS & 6.337 & 0.015 \\
\hline Insulin $120(\mu \mathrm{Ul} / \mathrm{ml})$ & $74.75 \pm 39.21^{\mathrm{a}}$ & $49.02 \pm 31.07^{\mathrm{a}}$ & 18.061 & $<0.001$ & $60.17 \pm 57.11^{b}$ & $40.74 \pm 28.91^{b}$ & 7.566 & 0.010 & 1.292 & NS \\
\hline HOMA-IR & $4.50 \pm 2.06^{c}$ & $4.00 \pm 2.11^{c}$ & 2.624 & NS & $3.24 \pm 1.61^{c}$ & $2.93 \pm 1.58^{c}$ & 1.250 & NS & 6.642 & 0.013 \\
\hline QUICKI & $0.31 \pm 0.02^{\mathrm{a}, \mathrm{c}}$ & $0.32 \pm 0.02^{\mathrm{a}, \mathrm{c}}$ & 6.070 & 0.021 & $0.33 \pm 0.03^{c}$ & $0.33 \pm 0.03^{c}$ & 1.666 & NS & 6.599 & 0.013 \\
\hline
\end{tabular}

Systolic blood pressure (SBP); diastolic blood pressure (DBP); total cholesterol (TC); triglycerides (TG); ${ }^{a}$ significant difference after 12 weeks in the group with metabolic syndrome; ${ }^{\mathrm{b}}$ significant difference after 12 weeks in the group without metabolic syndrome; ' significant difference in interaction effect between WMS and NMS groups. 


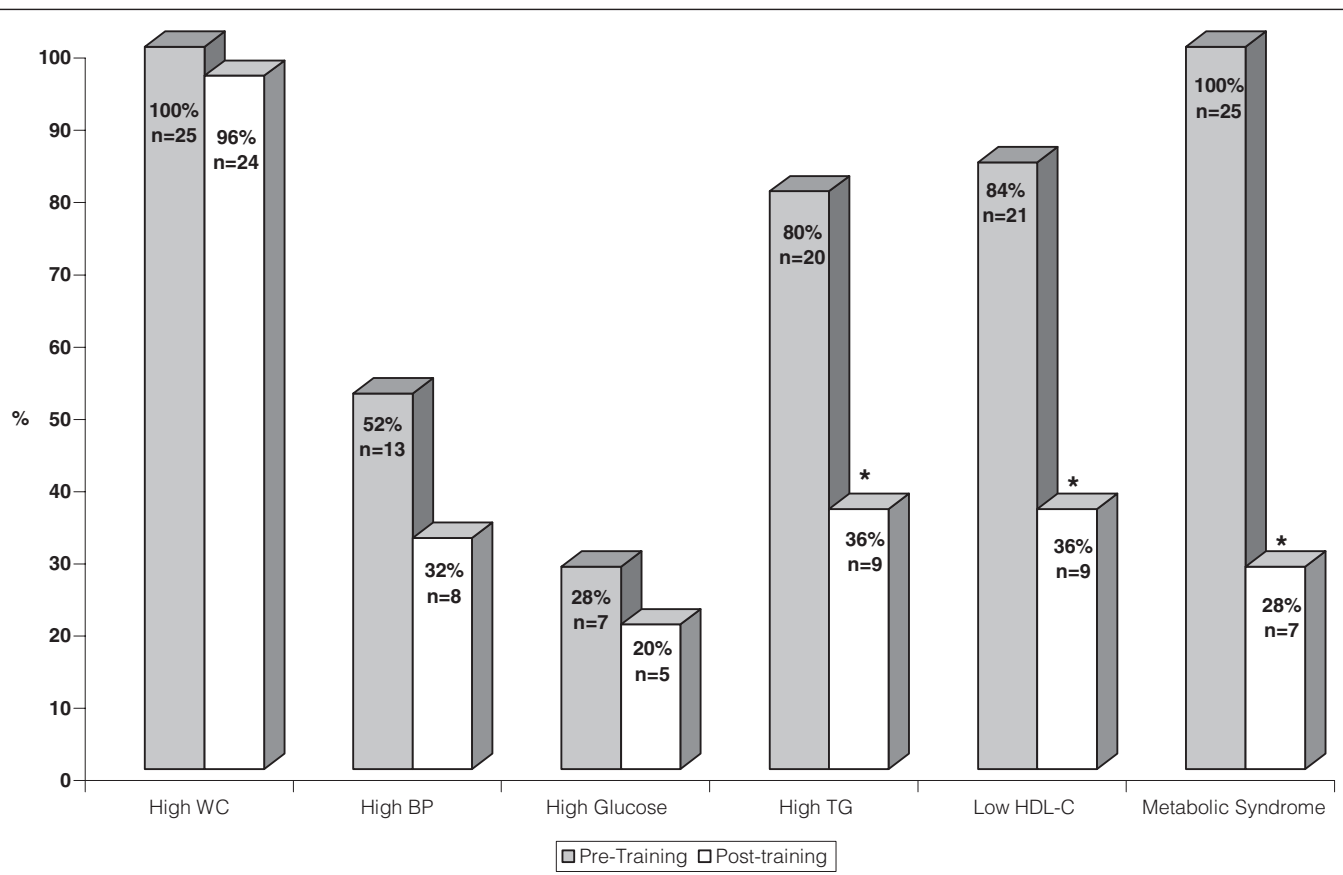

WC - waist circumference; BP - blood pressure; TG - triglycerides; * Significant level $p<0.05$

Figure 1. Variables in metabolic syndrome criteria before and after physical training in group with metabolic syndrome (WMS).

\section{Discussion $: \because$.}

The present study is in accordance with previous findings among adults ${ }^{6}$ and adolescents ${ }^{5,13,15}$, i.e. that a 12 -week physical training and nutritional guidance was successful in decreasing risk factors and metabolic syndrome among obese adolescents. These data must be viewed with caution because the criteria applied for diagnosing metabolic syndrome were derived from an adult population ${ }^{15}$. Recently, a criterion for diagnosing metabolic syndrome among adolescents was presented $^{36}$. However, regression analysis obtained from a healthy adult population was used and the data still need to be experimentally confirmed for adolescents. The present study acknowledges the importance of using adolescent data for diagnostic purposes; however, no other studies have applied such criteria and there is no evidence that the regression analysis reflects such populations. Thus, we preferred to compare the results from the present study with those conducted on adult populations.

The physical training prescription of the present study was based on the prescription by the American College of Sports Medicine (ACSM) ${ }^{37}$ for obese adults, and on previous research among obese pediatric populations. It has been suggested that moderate aerobic training at least twice a week for at least six weeks may improve the metabolic profile $e^{6,16,18}$ and cardiovascular fitness ${ }^{1,7,12,13,20,38}$.

Our proposal consisted of a workload of $120 \mathrm{~min} /$ week of moderate physical activity (40 to 75\% of VO2peak), divided into three weekly sessions, combined with nutritional guidance. The aim was to eliminate 500 kilocalories (kcal) from the calorie total of the diet for 12 weeks. Both the exercises and the nutritional guidance were effective in promoting important changes to a number of health-related parameters.

Anthropometric variables have been described as important risk factors and have been used as health indicators. Thus, changes in these variables may reflect a reduction in the degree of metabolic syndrome. Regular exercise has been reported to be an efficient way of reducing total body mass, BMI, BMI zscore, waist circumference, fat mass and \%BF among children and adolescents ${ }^{1,10,12,13,30}$. Among adults, a total body mass loss of $7 \%$ has been associated with reduced incidence of chronic degenerative diseases such as diabetes mellitus type II $^{39}$. Recently, some studies ${ }^{9,39}$ used a reduction of 0.5 in BMI z-score to evaluate the metabolic response to physical training among children and adolescents. Weiss et al. ${ }^{14}$ found that an increase of 0.5 in BMI zscore was associated with a greater chance of having metabolic syndrome in a pediatric population, but did not carry out an intervention program to change this parameter. The training program conducted in the present experiment was successful in reducing total body mass in both groups (obese participants with metabolic syndrome $=2.5 \%$ and those without the syndrome $=3 \%$ ) and BMI z-score (obese participants with metabolic syndrome $=0.47$ and those without the syndrome $=0.45$ ), nearing the recommended values ${ }^{9,14,40}$ by the end of the intervention period. The similar fat-free mass after the intervention period in the two groups has also been described in other studies ${ }^{12,41}$. Despite the 
decrease in total body mass among the obese adolescents, this last finding is an important result in our study, because it shows that lean mass was preserved in this multidisciplinary weight loss program. In addition, there were reductions in waist circumference (obese participants with metabolic syndrome $=3.3 \%$; those without the syndrome $=5.1 \%$ ). It has been suggested that this reduction is an important component that influences pediatric metabolic syndrome, as it reflects abdominal fat excess and is closely related to cardiovascular diseases ${ }^{41}$. Therefore, the data of the present study have provided arguments to conclude that obese adolescents' response to a program of physical activity consists of a change in visceral obesity and a decrease in the risk factors for metabolic syndrome.

$\mathrm{VO}_{2 \text { peak }}$ increases slightly with age during childhood. In contrast, there is a decrease in aerobic power and physical activity levels during adolescence ${ }^{1}$. Kaufman et al. ${ }^{13}$ showed that the response to aerobic training among sedentary overweight children is different ( $28 \%$ increase in $\left.\mathrm{VO}_{2 \text { peak }}\right)$ to the response among sedentary adolescents ${ }^{13}$, thus emphasizing the importance of the training effect and indicating that the increase in $\mathrm{VO}_{\text {2peak }}$ cannot be explained only by growth. Our results are in line with other studies, since both groups responded positively to exercise and presented increases in $\mathrm{VO}_{2 \text { peak }} \mathrm{L} / \mathrm{min}$ (obese participants with metabolic syndrome $=4.1 \%$ and those without the syndrome $=3.4 \%$ ) and a reduction in RHR. Improvements in cardiorespiratory parameters were also demonstrated by reductions in resting HR and the use of more intense workloads. Better heart and muscle function probably played a role in this improved performance ${ }^{37}$. There was an inverse relationship between aerobic fitness and fat content, in which both were significantly related to the lipid profile ${ }^{1}$. This reinforces the importance of exercise as a therapeutic strategy for reversing the adverse effects of lack of exercise among obese adolescents. It was reported previously ${ }^{41}$ that a multidisciplinary weight reduction program including regular exercise in combination with nutritional guidance may reduce total and abdominal adiposity and improve cardiorespiratory fitness, thereby preserving fat-free mass in obese adolescents.

Obesity has been correlated with higher levels of blood pressure, total cholesterol and triglycerides, and lower levels of HDL-C in youths ${ }^{1}$, particularly those with greater visceral adiposity ${ }^{42}$. The effects of exercise on cardiovascular risk factors among adults ${ }^{6}$ and pediatric populations ${ }^{11}$ have been investigated. Regular physical exercise may not reduce total cholesterol and LDL-C fraction levels, but it changes the quality of LDL-C subfractions, thereby increasing the concentrations of large LDL-C and reducing the concentration of small LDL-C ${ }^{11}$. The most significant effects of physical activities are observed in HDL-C and triglyceride levels ${ }^{1,3}$. Both groups in the present study improved their lipid profiles after the intervention, as reported by others ${ }^{3,7,11}$. The HDL-C levels increased by $17.65 \%$ among the obese participants with metabolic syndrome and by $18.56 \%$ among those without the syndrome. The triglyceride levels fell by $33.5 \%$ among the obese participants with metabolic syndrome and by $23.08 \%$ among those without the syndrome. In contrast, total cholesterol and LDL-C levels did not change after 12 weeks of intervention in either group. However, the benefits of regular exercise for reducing systolic blood pressure were more evident among the obese participants with metabolic syndrome. The positive changes found in our study can be explained by better body fat distribution (reductions in total body mass and waist circumference, and unchanged fat-free mass) and increased physical fitness due to training. Physical training and nutritional guidance probably produced a healthy lifestyle.

There are few studies describing the effects of physical exercises and balanced eating habits on insulinemia among children and adolescents ${ }^{7,11}$. Physical activity enhances the insulin action/effect because of several adaptive mechanisms in muscle, adipose, hepatic and endothelial tissues ${ }^{43}$. Hardin et al. ${ }^{3}$ found a reduction in fasting insulinemia in participants who followed a physical training or diet program, compared with a control group. Reinehr et al. ${ }^{40}$ studied 42 obese children and showed that after a one-year intervention, including physical activity and nutritional education, there was a reduction in insulinemia and HOMA-IR only among those whose reductions in BMI z-score were $\geq 0.5$. In a study by Kang et al. ${ }^{11}$, obese participants aged 13 to 16 years followed an eight-month physical training and nutritional guidance program and did not show any changes in fasting insulinemia, probably because they did not present significant reductions in \%BF and abdominal adiposity. In the present study, both groups showed reductions in total body mass, \%BF and waist circumference; however, their baseline insulin and HOMA-IR levels were unchanged after the physical training and nutritional guidance. In contrast, both groups showed decreased glucose and insulin levels after 120 min of glucose overload. The reductions were probably associated with better adaptive mechanisms in tissues, which caused the glucose overload to disappear quickly. In addition, the obese participants with metabolic syndrome showed increases in QUICKI after the 12-week intervention, thus indicating improvement in insulin sensitivity. The benefits of physical training are more evident among participants who suffered from previous vascular or lipid modifications, in comparison with those without such complications ${ }^{11,21}$.

The results from the present study must be viewed with caution because of the short duration of the intervention and the small number of participants; however, our study applied a multidisciplinary program as therapeutic treatment for adolescents 
with metabolic syndrome. One limitation of our study was the lack of a control group without physical exercise or nutritional guidance. However, it should be mentioned that the original objective of the present study was to compare the effects of physical exercise and nutritional guidance on metabolic syndrome among obese adolescents and controls without metabolic syndrome. Finally, the exercise prescription in this study focused only on $\mathrm{VO}_{2}$; it did not evaluate the ventilatory threshold.

Among pediatric populations, there are few interventional studies with physical training, and these only evaluated the effect on individuals' cardiovascular risk factors ${ }^{3}$. Among adults, exercise seems to reduce metabolic syndrome ${ }^{6}$. The present study proved that this intervention was beneficial because it caused reductions in the risk factors for metabolic syndrome among adolescents. Our data showed that $72 \%$ of the adolescents who had been diagnosed as presenting metabolic syndrome were no longer classified as such after the intervention program. These results indicate that physical training and nutritional guidance constitute a successful therapeutic intervention for obese adolescents with metabolic syndrome, thereby decreasing their risk factors for developing cardiovascular diseases.

\section{Conclusion : : :}

The adolescents with metabolic syndrome had a decrease in risk factors through the improvement of physical fitness and metabolic profile after a period of intervention in which physical training and nutritional guidance were provided. The benefits from increased insulin sensitivity were evident among the obese adolescents who had shown previous abnormalities in insulin resistance. The effects of multidisciplinary intervention are important as preventive measures and therapeutic procedures for obese children and adolescents in order to improve their physical fitness and metabolic profile. Healthy lifestyles, dietary changes and regular physical activity need to be promoted in obese pediatric populations.

\section{References $: \because$.}

1. Thomas NE, Cooper SM, Williams SP, Baker JS, Davies B. Relationship of fitness, fatness, and coronary-heart-disease risk factors in 12- to 13-yearolds. Pediatr Exerc Sci. 2007;19(1):93-101.

2. Halley Castillo E, Borges G, Talavera JO, Orozco R, Vargas-Aléman C, Huitrón-Bravo G, et al. Body mass index and the prevalence of metabolic syndrome among children and adolescents in two mexican populations. J Adolesc Health. 2007;40(6):521-6.

3. Hardin DS, Hebert JD, Bayden T, Dehart M, Mazur L. Treatment of childhood syndrome X. Pediatrics. 1997;100(2):E5.

4. McGillis-Bindler RC, Massey LK, Shultz JA, Mills PE, Short R. Metabolic syndrome in a multiethnic sample of school children: implications for the pediatric nurse. J Pediatr Nurs. 2007;22(1):43-58.

5. Katzmarzyk PT, Leon AS, Wilmore JH, Skinner JS, Rao DC, Rankinen T, et al. Targeting the metabolic syndrome with exercise: evidence from the HERITAGE family study. Med Sci Sports Exer. 2003;35(10):1703-9.

6. Nishijima H, Satake K, Igarashi K, Morita N, Kanazawa N, Okita K. Effects of exercise in overweight Japanese with multiple cardiovascular risk factors. Med Sci Sports Exer. 2007;39(6):926-33.

7. Ferguson MA, Gutin B, Le N, Karp W, Litaker M, Humphries M, et al. Effects of exercise training and its cessation on components of the insulin resistance syndrome in obese children. Int J Obes Relat Metab Disord. 1999;23(8):889-95.

8. Freedman DS, Serdula MK, Srinivasan SR, Berenson GS. Relation of circumferences and skinfold thicknesses to lipid and insulin concentrations in children and adolescents: the bogalusa heart study. Am J Clin Nutr. 1999;69(2):308-17.

9. Reinehr T, Kiess W, Kapellen T, Andler W. Insulin sensitivity among obese children and adolescents, according to degree of weight loss. Pediatrics. 2004;114(6):1569-73.

10. Knöpfli BH, Radtke T, Lehmann M, Schätzle B, Eisenblätter J, Gachnang A, et al. Effects of a multidisciplinary inpatient intervention on body composition, aerobic fitness, and quality of life in severely obese girls and boys. J Adolesc Health. 2008;42(2):119-27.

11. Kang HS, Gutin B, Barbeau P, Owens S, Lemmon CR, Allison J, et al. Physical training improves insulin resistance syndrome markers in obese adolescents. Med Sci Sports Exerc. 2002;34(12):1920-7.

12. Gutin $B$, Barbeau $P$, Owens $S$, Lemmon $C R$, Bauman M, Allison J, et al. Effects of exercise intensity on cardiovascular fitness, total body composition, and visceral adiposity of obese adolescents. Am J Clin Nutr. 2002;75(5):818-26.

13. Kaufman C, Kelly AS, Kaiser DR, Steinberger J, Dengel DR. Aerobic-exercise training improves ventilatory efficiency overweight children. Pediatr Exerc Sci. 2007;19(1):82-92.

14. Weiss R, Dziura J, Burgert TS, Tamborlane WV, Taksali SE, Yeckel CW, et al. Obesity and the metabolic syndrome in children and adolescents. N Engl J Med. 2004;350(23):2362-74.

15. Third Report of the National Cholesterol Education Program (NCEP) [homepage na internet]. Expert Panel on Detection, Evaluation and 
Treatment of High Blood Cholesterol in Adults (Adult Treatment Panel III): Final Report 2002. Bethesda, Md: National Heart, Lung and Blood Institute [atualizada em 2004; acesso em 2004 Out 20]. Disponível em: http:/www.nhlbi.nih.gov/guidelines/cholesterol/atp3full.pdf.

16. Cook S, Weitzman M, Auinger P, Nguyen M, Dietz WH. Prevalence of a metabolic syndrome phenotype in adolescents: Findings from the Third National Health and Nutrition Examination Survey 1988-1994. Arch Pediatr Adolesc Med. 2003;157(8):821-7.

17. de Ferranti SD, Gauvreau K, Ludwig DS, Neufeld EJ, Newburger JW, Rifai $N$. Prevalence of the metabolic syndrome in american adolescents findings from the Third Nacional Health ande Nutrition Examination Survey. Circulation. 2004;110(16):2494-7.

18. Molnár $\mathrm{D}$. The prevalence of the metabolic syndrome and type 2 diabetes mellitus in children and adolescents. Int $\mathrm{J}$ Obes Relat Metab Disord. 2004;28 Suppl 3:S70-4

19. Caranti D, de Melo MT, Prado WL, Tock L, Siqueira KO, de Piano A, et al. Short and long term beneficial effects of multidisciplinary therapy for the control of metabolic syndrome in obese adolescents. Metabolism. 2007;56(9):1293-300.

20. Deforche B, De Bourdeaudhuij I, Debode P, Vinaimont F, Hills AP, Verstraete $S$, et al. Changes in fat mass, fat-free mass and aerobic fitness in severely obese children and adolescents following a residential treatment programme. Eur J Pediatr. 2003;162(9):616-22.

21. Ferguson MA, Gutin B, Owens S, Barbeau P, Tracy RP, Litaker M. Effects of physical training and its cessation on the hemostatic system of obese children. Am J Clin Nutr. 1999;69(6):1130-4.

22. Kuczmarski RJ, Ogden CL, Grummer-Strawn LM, Flegal KM, Guo SS, Wei R, et al. CDC growth charts: United States. Adv Data. 2000;8(314):1-27.

23. Férnandez JR, Redden DT, Petrobelli A, Allison DB. Waist circumference percentiles in nationally representative samples of African-American, European-American, and Mexican-American children and adolescents. J Pediatr. 2004;145(4):439-44.

24. Houtkooper LB, Going SB, Lohman TG, Roche AF, Van Loan M. Bioelectrical impedance estimation of fat-free body mass in children and youth: A crossvalidation study. J Appl Physiol. 1992;72(1):366-73.

25. Sociedade Brasileira de Cardiologia. I Diretriz de prevenção da aterosclerose na infância e adolescência. Arq Bras Cardiol. 2005;85 Suppl VI:S1-36.

26. Associação Médica Brasileira e Conselho Federal de Medicina Projeto Diretrizes: Diabetes Mellitus: classificação e diagnóstico.[homepage na Internet]. São Paulo: Sociedade Brasileira de Endocrinologia e Metabologia. [atualizada em 2004; acesso em 2005 April 14] Disponível em: http://www. projetodiretrizes.org.br/4_volume/06-diabetes-c.pdf.

27. Sociedade Brasileira de Cardiologia. Sociedade Brasileira de Hipertensão. V Diretrizes Brasileiras de Hipertensão Arterial. Rev Bras Hipertens. 2006;13(4):256-312.

28. Matthews DR, Hosker JP, Rudenski AS, Naylor BA, Treacher DF, Turner RC. Homeostasis model assessment: insulin resistance and beta-cell function from fasting plasma glucose and insulin concentrations in man. Diabetologia. 1985;28(7):412-9.
29. Katz A, Nambi SS, Mather K, Baron AD, Follmann DA, Sullivan G, et al. Quantitative insulin sensitivity check index: a simple, accurate method for assessing insulin sensitive in humans. J Clin Endocrinol Metab. 2000;85(7):2402-10.

30. National High Blood Pressure Education Program Working Group on High Blood Pressure in Children and Adolescents. The fourth report on the diagnosis, evaluation, and treatment of high blood pressure in children and adolescents. Pediatrics. 2004;114(2 Suppl 4):555-76.

31. Bar-Or 0. Pediatric sports medicine for the practitioner. New York: SpringerVerlag; 1983.

32. Rowland TW. Aerobic testing protocols: Pediatric Laboratory exercise testing. Clinical guidelines. Champaign, IL: Human Kinetics; 1993.

33. Tinker LF, Patterson RE, Kristal AR, Bowen DJ, Kuniyuki A, Henry H, et al. Measurement characteristics of 2 different self-monitoring tools used in a dietary intervention study. J Am Diet Assoc. 2001;101(9):1031-40.

34. Wheeler ML, Franz M, Barrier P, Holler H, Cronmiller N, Delahanty LM Macronutrient and energy database for the 1995 Exchange Lists for Meal Planning: a rationale for clinical practice decisions. J Am Diet Assoc. 1996;96(11):1167-71.

35. Tanner JM. Normal growth and techniques of growth assessment. Clin Endocrinol Metab. 1986;15(3):411-51.

36. Jolllife CJ, Janssen I. Development age-specific adolescent metabolic syndrome criteria that are linked to the Adult Treatment Panel III and International Diabetes Federation Criteria. J Am Coll Cardiol. 2007;49(8):891-8

37. American College of Sports Medicine. ACSM'S Guidelines for Exercise Testing and Prescription. $7^{\text {a }}$ ed. Philadelphia: Lippincott Williams \& Wilkins; 2006.

38. Shaibi GQ, Cruz ML, Ball GD, Weigensberg MJ, Kobaissi HA, Salem GJ, et al. Cardiovascular fitness and the metabolic syndrome in overweight latino youths. Med Sci Sports Exer. 2005;37(6):922-8.

39. Knowler WC, Barrett-Connor E, Fowler SE, Hamman RF, Lachin JM, Walker EA, et al. Diabetes Prevention Program Research Group. Reduction in the incidence of type 2 diabetes with lifestyle intervention or metformin. N Engl J Med. 2002;346(6):393-403.

40. Reinehr T, Roth C, Menke T, Andler W. Adiponectin before and after weight Ioss in obese children. J Clin Endocrinol Metab. 2004;89(8):3790-4.

41. Dao HH, Frelut ML, Peres G, Bourgeois P, Navarro J. Effects of a multidisciplinary weight loss intervention on anaerobic and aerobic aptitudes in severely obese adolescents. Int J Obes Relat Metab Disord. 2004;28(7):870-8.

42. Lee S, Bacha F, Arslanian SA. Waist circumference, blood pressure, and lipid components of the metabolic syndrome. J Pediatr. 2006;149(6): 809-16.

43. Brage S, Wedderkopp N, Ekelund U, Franks PW, Wareham NJ, Andersen $\mathrm{LB}$, et al. Objectively measured physical activity correlates with indices of insulin resistance in Danish children. Int J Obes Relat Metab Disord. 2004;28(11):1503-8. 